\title{
A Potential Snail Host of Schistosomiasis in Bolivia: Biomphalaria amazonica Paraense, 1966
}

\author{
JP Pointier/+, WL Paraense*, RJ Dejong**, ES Loker**, MD Bargues***, S Mas-Coma***
}

Laboratoire de Biologie Marine et Malacologie, EPHE, UMR 5555 du CNRS, Université de Perpignan, 52 Avenue de Villeneuve, 66860, Perpignan, France *Departamento de Malacologia, Instituto Oswaldo Cruz-Fiocruz, Rio de Janeiro, RJ, Brasil **Department of Biology, University of New Mexico, Albuquerque, NM, USA ***Departamento de Parasitología, Facultad de Farmacia,

Universidad de Valencia, Burjassot-Valencia, España

Biomphalaria amazonica Paraense, 1996 was collected from a permanent pond in the outskirts of the Bolivian city of Santa Cruz. Identification of the collected specimens was made by comparison with the original description of the species and with topotypic material in the collection of Instituto Oswaldo Cruz. Phylogenetic analysis confirmed that these Bolivian specimens belong to $\mathrm{B}$. amazonica.

Key words: Biomphalaria amazonica - Bolivia

Biomphalaria amazonica was described by Paraense (1966) from material collected in 1964 in Igarapé da Cachoeirinha on the outskirts of Manaus and in Careiro Island, situated on the Amazon river at its confluence with the Rio Negro, State of Amazonas, Brazil. Other records were reported in the following years extending the geographical distribution of the species to the Brazilian states of Acre, Rondônia (Paraense 1983), Mato Grosso (Paraense \& Corrêa 1985) and Mato Grosso do Sul (Dorval \& Silva 1990).

In 1997 a small planorbid snail was collected by some of us in Bolivia from the Santa Cruz area. This snail was included under the name of Biomphalaria sp. in a phylogenetic analysis of the most important snail hosts of schistosomes, using partial mitochondrial ribosomal 16S and complete nuclear ribosomal ITS1 and ITS2 nucleotide sequences (DeJong et al. 2001). That study showed a strong genetic similarity of this snail with two Brazilian samples of B. amazonica from Amazonas and Rondônia respectively, suggesting that they belong to the same species.

$B$. amazonica has not been found naturally infected with Schistosoma mansoni, but proved susceptible under experimental conditions (Corrêa \& Paraense 1971, Paraense \& Corrêa 1985), being considered a poor host like $B$. straminea. However, this latter species is admittedly a good vector of the parasite in hyperendemic areas of Northeastern Brazil (Corrêa \& Paraense 1971, Paraense $\&$ Corrêa 1985). Thus, the occurrence of B. amazonica in Bolivia points to the risk of introduction of schistosomiasis mansoni into another South American country.

This work was supported in part by funding from the STD program of the Commission of the European Community (DG XII: Science, Research and Development) (Contract no. TS3CT94-0294) and from NIH grant AI44913.

${ }^{+}$Corresponding author. Fax: +33-(0)4-6850.3686. E-mail: pointier@univ-perp.fr

Received 20 March 2002

Accepted 24 April 2002
Conchological and anatomic characteristics are presented and compared with the description by Paraense (1966) of the type specimens of B. amazonica. The data from morphology and phylogenetic analysis confirmed the identity of the Bolivian specimens with B. amazonica.

\section{MATERIALS AND METHODS}

The Bolivian material was collected in October, 1997, from a permanent pond used for watering cattle located in a private farm in Warnes $\left(17^{\circ} 30^{\prime} \mathrm{S}, 6^{\circ} 10^{\prime} \mathrm{W}\right)$, a small locality about $30 \mathrm{~km}$ to the north of Santa Cruz de la Sierra, in the way from Santa Cruz to Cochabamba. The pond harbored two planorbid species, B. amazonica and Helisoma duryi (Wetherby, 1879). The snails were collected with a sieve, and allowed to relax overnight using menthol. They were then immersed for $40 \mathrm{sec}$ in water heated at $70^{\circ} \mathrm{C}$, from which they were transferred to water at room temperature. The soft parts were drawn from the shell with a small forceps and fixed in slightly modified Railliet-Henry fluid (distilled water $930 \mathrm{ml}$, sodium chloride $6 \mathrm{~g}$, formalin $50 \mathrm{ml}$, glacial acetic acid $20 \mathrm{ml}$ ). Voucher specimens were deposited in the Museum National d'Histoire Naturelle de Paris (Laboratoire de Biologie des Invertébrés Marins), in the École Pratique des Hautes Études of Perpignan (Laboratoire de Biologie Marine et Malacologie), and in the Malacological Collection of Instituto Oswaldo Cruz.

Sequences used for phylogenetic analysis were from DeJong et al. (2001) and consisted of ITS1, ITS2, and partial mtDNA $16 \mathrm{~S}$ from the taxa referred to as the "speciesrich Neotropical" group (GenBank AY30377-AY30392 and AY30210-AY30223), plus B. obstructa as an outgroup (AY30229, AY30398). The taxa chosen included the specimen from Bolivia, B. amazonica specimens from Brazil, and other Neotropical species most likely to be related to the specimen in question. A lower number of taxa allowed for the inclusion of more characters from the data set, because a few sequence regions that previously had been unalignable across a wider range of Biomphalaria species (DeJong et al. 2001) were now readily aligned. Several regions remained unalignable and were excluded from the analyses. Maximum parsimony (MP), minimum evolution (ME), and maximum likelihood (ML) analyses were 
performed using PAUP* 4.0b8a (Swofford 1998) as in DeJong et al. (2001), except the ML analyses used a more complex general-time-reversible model (GTR+I+G). Nodal support was assessed with bootstrap analysis, with 1000 replicates performed for MP and ME and 100 performed for ML analyses. This data set had a total of 1447 sites, of which 152 were parsimony informative.

\section{RESULTS}

All the collected specimens fit well, in shell (Fig. 1) and anatomical (Fig. 2) characteristics, with the description given by Paraense (1966). The main shell quantitative characteristics were measured on 20 full-grown snails: diameter 6.0-9.1 mm (mean 7.34; SD 0.81); height 2.1-2.7 (mean 2.48; SD 0.21); ratio of diameter to height of shell 2.74-3.24 (mean 2.97; SD 0.16). These characteristics are quite similar to those given by Paraense (1966) for $B$. amazonica: diameter 7-8 mm (7.3); height 2.2-2.6 (2.41); ratio of diameter to height of shell 2.84-3.30 (3.03).

The reproductive system includes the following reliable characteristics (Fig. 2): penis sheath shorter than the prepuce (ratio 0.54-0.78; mean 0.64, SD 0.07) as observed for B. amazonica (ratio 0.33-0.67); prostate with 9-14 diverticula arranged in a row (8-12 diverticula in $B$. amazonica); the morphology of the diverticula fit well with the description given by Paraense (1966) for $B$. amazonica: "the stalks of the diverticula are rather wide, nearly always short and little interspaced, dividing into two short primary branches, each of which may put forth usually two slightly elongate, ovoid or more rudimentary buds. The branches of the diverticula spread a little laterally and barely overlap one another"; the vagina is short and wide and a bulgy pouch is clearly visible as in B. amazonica.

The ML tree is shown in Fig. 3. Maximum parsimony and ME analyses yielded similar trees. Bootstrap support values for the grouping of the specimen from Bolivia with the other B. amazonica are all very high (99/100/100; Fig. $3)$, giving strong evidence that the specimen in question is $B$. amazonica. There was never any tendency for it to group with any taxon besides $B$. amazonica.

\section{THE RANGE OF B. AMAZONICA}

The Bolivian village of Warnes lies near the Piray river, an affluent of the Mamoré, about $800 \mathrm{~km}$ south from the town of Guajará-mirim, where B. amazonica was collected by Paraense (1983).

B. amazonica ranges for about $1,200 \mathrm{~km}$ along the Amazon river, from Benjamin Constant and Tabatinga ( $\left.4^{\circ} 22^{\prime} \mathrm{S}, 70^{\circ} 02^{\prime} \mathrm{W}\right)$ to Careiro (3 $12^{\prime}$ ' S, 59 $\left.45^{\circ} \mathrm{W}\right)$, besides about $900 \mathrm{~km}$ from Tarauacá and Feijó (state of Acre),

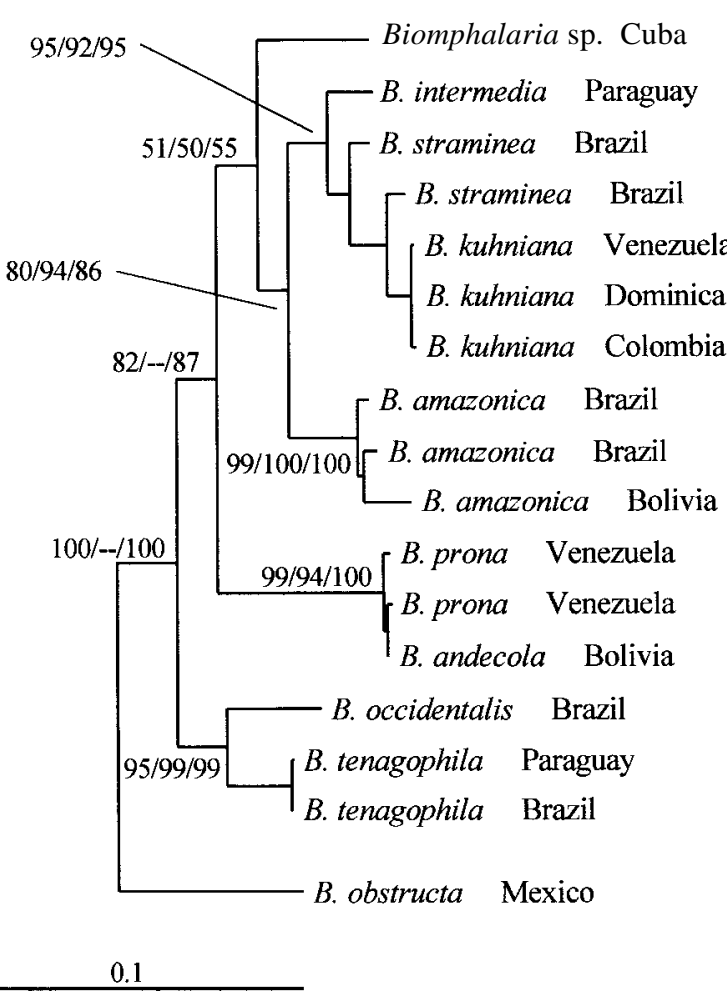

Fig. 3: maximum likelihood tree; bootstrap support values are displayed for major branch nodes (maximum parsimony/minimum evolution/maximum likelihod; dashes indicate $<50 \%$ support).
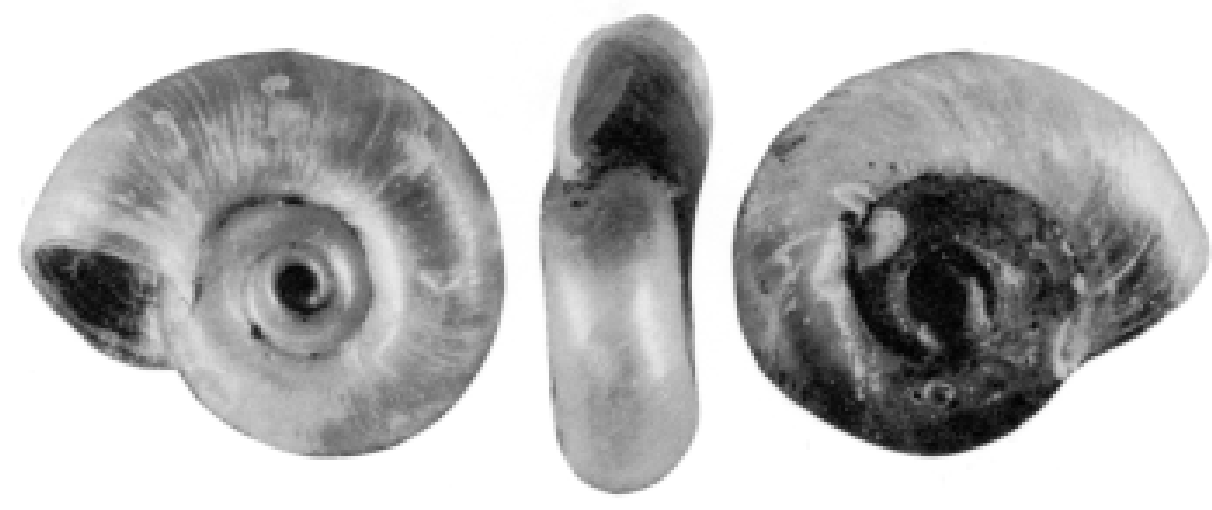

$5 \mathrm{~mm}$

Fig. 1: shell of Biomphalaria amazonica from Warnes, Bolivia. 


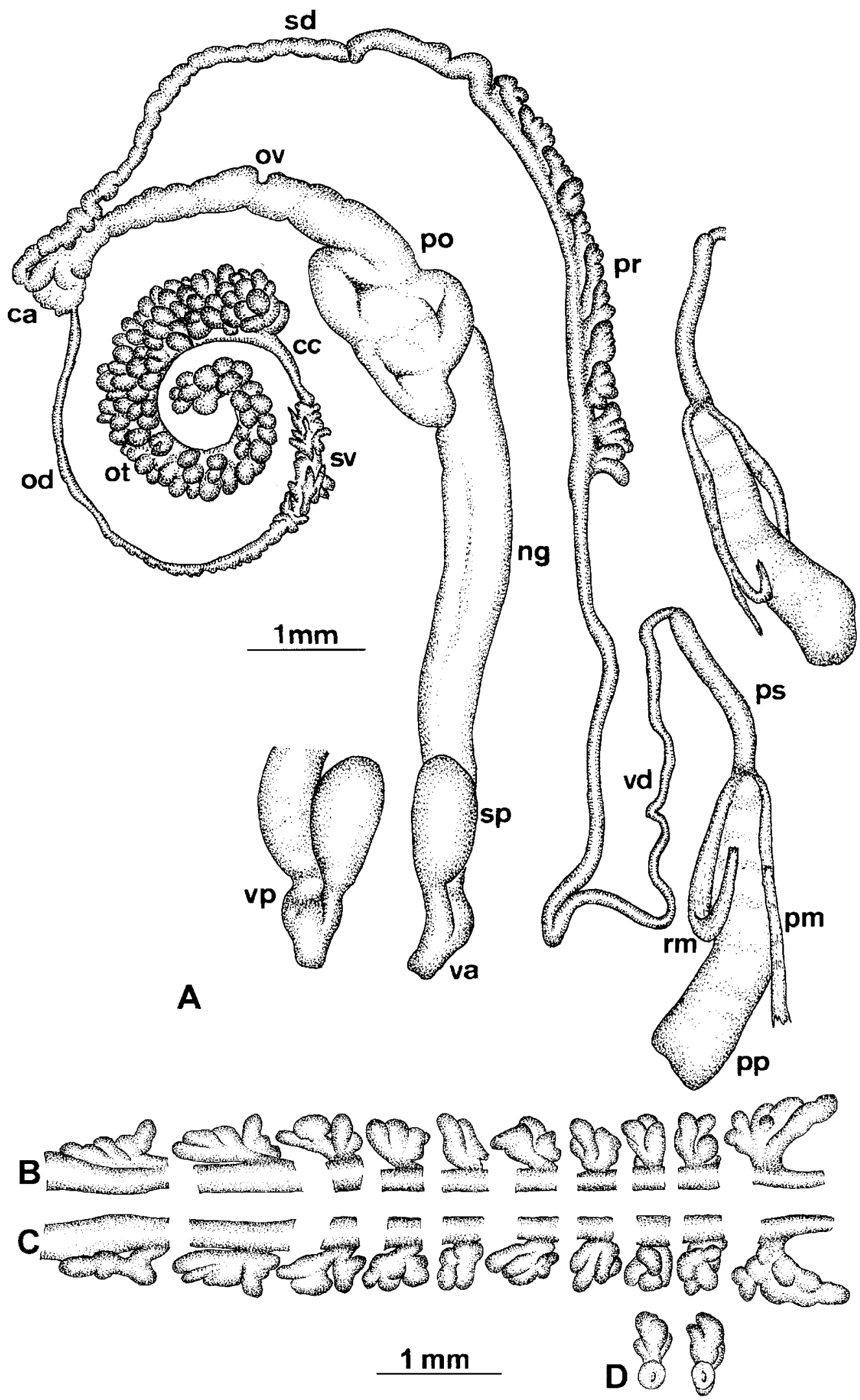

Fig. 2A: reproductive system of Biomphalaria amazonica from Warnes, Bolivia $(\mathrm{ca}=$ carrefour; $\mathrm{cc}=$ collecting canal of ovotestis; $\mathrm{ng}=$ nidamental gland; od = ovispermiduct; ot = ovotestis; ov = oviduct; $\mathrm{pm}=$ protractor muscle of prepuce; po = pouch of oviduct; $\mathrm{pp}=$ prepuce $; \mathrm{pr}=$ prostate $; \mathrm{ps}=$ penis sheath $; \mathrm{rm}=$ retractor muscle of prepuce; $\mathrm{sd}=$ spermiduct; $\mathrm{sp}=$ spermatheca; $\mathrm{sv}=$ seminal vesicle; $\mathrm{va}=$ vagina; $\mathrm{vd}=$ vas deferens; $\mathrm{vp}=$ vaginal pouch); $\mathrm{B}$ : prostate diverticula, free lateral surface; $\mathrm{C}$ : prostate diverticula, side adherent to nidamental gland; D: prostate diverticula as seen from interproximal sides. 


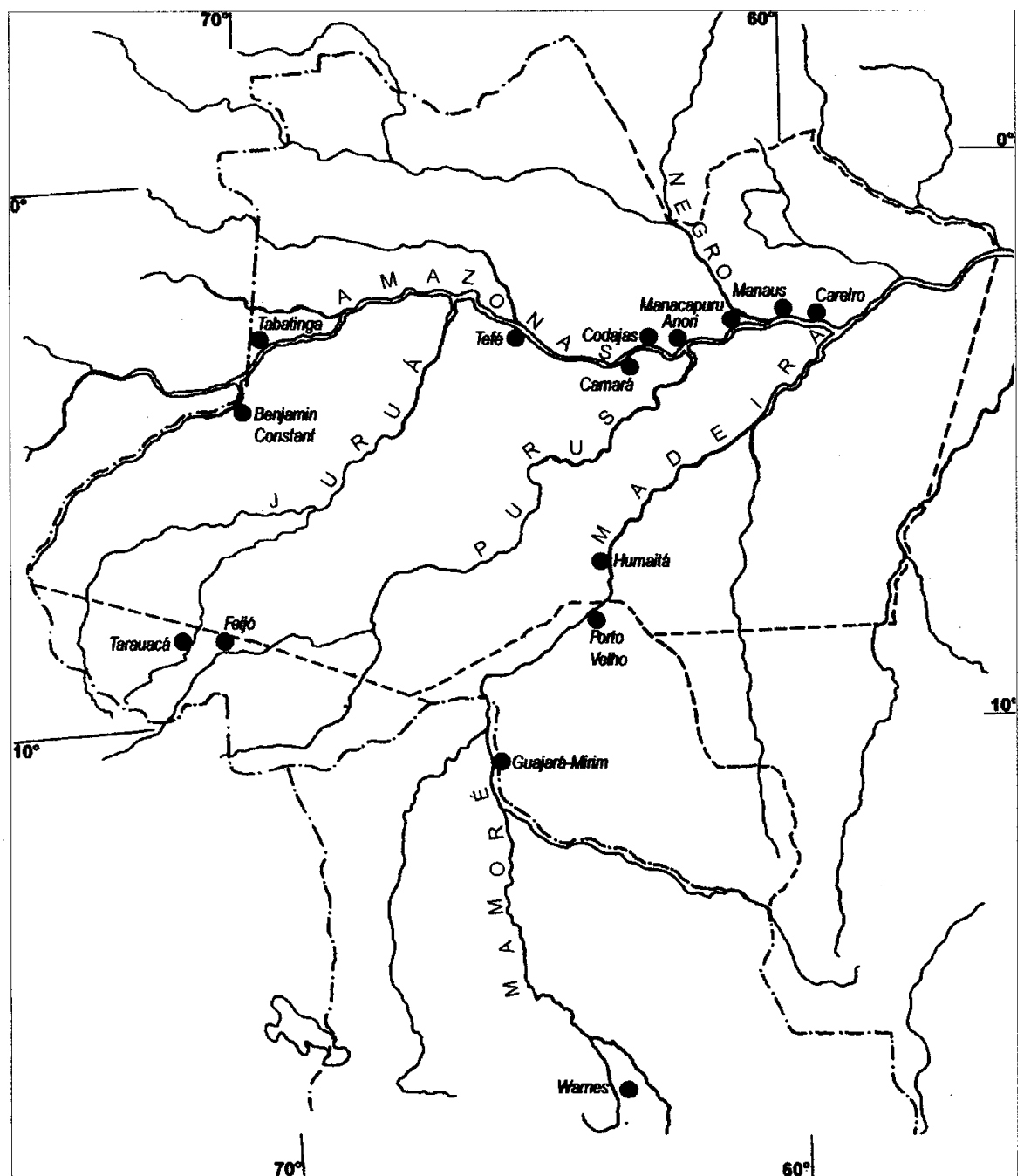

Fig. 4: present distribution of Biomphalaria amazonica; occurrence in Barão de Melgaço (Mato Grosso) and Aquidauana (Mato Grosso do Sul) not figured.

through the Juruá river, to the Amazon. Thus it should not be surprising if further investigation reveals its presence in numerous intervening localities. Fig. 4 shows the known distribution of the species, according to the present finding and to data from Paraense (1983).

Besides the Amazon basin B. amazonica was recorded from Barão de Melgaço ( $16^{\circ} 13^{\prime}$ S, 55 $\left.58^{\circ} \mathrm{W}\right)$, State of Mato Grosso (Paraense \& Corrêa 1985) and from Aquidauana $\left(20^{\circ} 28^{\prime} \mathrm{S}, 55^{\circ} 48^{\prime} \mathrm{W}\right)$, State of Mato Grosso do Sul (Dorval \& Silva 1990), situated respectively on the Cuiabá and Aquidauana rivers, tributaries of the La Plata system.

\section{REFERENCES}

Corrêa LR, Paraense WL 1971. Susceptibility of Biomphalaria amazonica to infection with two strains of Schistosoma mansoni. Rev Inst Med Trop S Paulo 13: 387-390.

DeJong RJ, Morgan JAT, Paraense WL, Pointier JP, Amarista M, Ayeh-Kumi PFK, Babiker A, Barbosa CS, Brémond P, Canese AP, de Souza CP, Dominguez C, File S, Gutierrez A, Incani RN, Kawano T, Kazibwe F, Kpikpi J, Lwambo NJS, Mimpfound R, Njiokou F, Poda JN, Sene M,
Velásquez LE, Yong M, Adema CM, Hofkin BV, Mkoji GM, Loker ES 2001. Evolutionary relationships and biogeography of Biomphalaria (Gastropoda: Planorbidae) with implications regarding its role as host of the human bloodfluke, Schistosoma mansoni. Mol Biol Evol 18: 22252239.

Dorval MEC, Silva RP 1990. Biomphalaria amazonica Paraense, 1966 in the State of Mato Grosso do Sul, Brazil (Mollusca, Pulmonata, Planorbidae). Mem Inst Oswaldo Cruz 85: 117118.

Paraense WL 1966. Biomphalaria amazonica and B. cousini, two new species of Neotropical planorbid molluscs. Rev Brasil Biol 26: 115-126.

Paraense WL 1983. A survey of planorbid molluscs in the Amazonian region of Brazil. Mem Inst Oswaldo Cruz 78: 343-361.

Paraense WL, Corrêa LR 1985. Further experiments on susceptibility of Biomphalaria amazonica to Schistosoma mansoni. Mem Inst Oswaldo Cruz 80: 259-262.

Swofford DL 1998. PAUP*: phylogenetic analysis using parsimony (*and other methods). Version 4.0b8a. Sinauer, Sunderland, Massachusetts, USA. 